\title{
Distortion of uniform electric field by human body of technical personal in substations with super high voltages $330-500 \mathrm{kv}$
}

\section{S. Okrainskaya}

Department: The Safety of Life, South Ural State University (National Research University), Chelyabinsk, Russia South Ural State University (National Research University), SUSU, Chelyabinsk, Russia

\section{Email adress:}

okrainskaya@yandex.ru (I. S. Okrainskaya)

\section{To cite this article:}

I. S. Okrainskaya. Distortion of Uniform Electric Field by Human Body of Technical Personal in Substations with Super High Voltages 330-500 kv. International Journal of Energy and Power Engineering. Vol. 2, No. 1, 2013, pp. 18-28. doi: 10.11648/j.ijepe.20130201.13

\begin{abstract}
For protection electric substations personnel from harmful effects of the super high voltage electric field, it is need to measure the level and time of electric field exposition of personal by using mobile electric field measurement instrument. The instrument are placed in mans helmet close to a head in area of high electric field intensity. Standards for limited vales of electric field intensity are estimated for undistorted electric field. As a conductor, the human body distorts the original electric field around the body and device shows distorted value of electric field. Investigation of level distortion by the finite element method and the experimental measurements shows that the maximum distortion appears with change of height of the person and at change parameters of foot ware soil. These parameters, height of the person and foot ware soil data should be used for design of a measurement devise and for adjustment the device before measurements. Change of other person parameters can be ignored because of very law level of changes field distortion.
\end{abstract}

Keywords: Electric Field, Distortion, Anthropometric Characteristics

\section{Introduction}

This paper is revised and extended version of the paper [7]. Electrical system with super high voltage is a source of a harmful, non-uniformly distributed in space, $50 \mathrm{~Hz}$ frequency electric field. The electric field intensity at some points of on open area substations can be $30 \mathrm{kV} / \mathrm{m}$. This value significantly exceeds the maximum allowable level $5 \mathrm{kV} / \mathrm{m}$ on working place during working day [1]. Maintenance of the electrical installations in power substation is associated with the necessity of constant worker movement in this field during inspections of equipment and operating switches. Screening devices are only partially protect the staff and the use of individual screening costumes creates additional inconvenience for the personnel related to the lost of time for change costumes and some discomfort or even overheating during warmer months. It is much more efficient and convenient method would be to use "protection by time". This method assumes control of the time residence of a worker in the zone of the electric field with electric field intensities $5 \mathrm{kV} / \mathrm{m}$ to $20 \mathrm{kV} / \mathrm{m}$ [2]. The permitted staying time of the personnel within a working day is calculated under the formula.

$$
\mathrm{T}_{\mathrm{add}}=8 \cdot\left(\mathrm{t}_{\mathrm{E} 1} / \mathrm{T}_{\mathrm{E} 1}+\mathrm{t}_{\mathrm{E} 2} / \mathrm{T}_{\mathrm{E} 2}+\ldots+\mathrm{t}_{\mathrm{En}} / \mathrm{T}_{\mathrm{En}}\right)
$$

Here, $t_{E 1}, t_{E 2}, \ldots, t_{E n}$ are residence times in the area with electric field intensities $E_{1}, E_{2}, \ldots, E_{n} ; T_{E 1}, T_{E 2}, \ldots, T_{E n}$ are the maximum value of time permitted in areas with intensities $E_{1}, E_{2}, \ldots, E_{n}$. The time $\left(T_{a d d}\right)$ is equivalent, according to the biological effect, of staying in the electric field at border of the permitted electric field intensity $5 \mathrm{kV} / \mathrm{m}$. The calculated time $\left(\mathrm{T}_{\mathrm{add}}\right)$ should not exceed eight hour (working day). Control of the time residence involves the measurement of electric field intensity at a position of the man location, and measurement the time, spent at this point. The body of the person consists of the fabrics having high conductivity and, as any conductor, causes distortion of an electric field [4] around the body. Working normative document [2] establish maximum permissible levels for the person in an electric undistorted human body field. So, the measured (distorted) values of electric field must be recalculated to equivalent undistorted for use in equation 1 . The purpose of this paper is the investigation of the electric field distortion by a human body with different parameters person: 
height, dimension head and breast, and position arms, and also investigation of the electric field distortion by a human body with different properties of the footwear soil.

The modern electronic elements base allows create devices for a measurement electric field. Devise should have low weight, size, and small power consumption.

The most reasonable location for the sensor of a mobile device is a helmet (Fig. 1), because it is the place with maximum electric field intensity. The employee admitted to perform work on an open area of substation or near power lines is always provided by a helmet regardless type of the work and time of a year. In this case, the sensor of the mobile device is placed at distance of few centimeters from the surface of the person head in the area of high distortion of the electric field. Calculations of electric field distortion fulfilled below were carried out from distance $2 \mathrm{~cm}$ from a surface of a person head. At accommodation of the mobile device in a worker helmet, it is necessary to keep a vertical safe gap $2 \mathrm{~cm}$ between device and head.

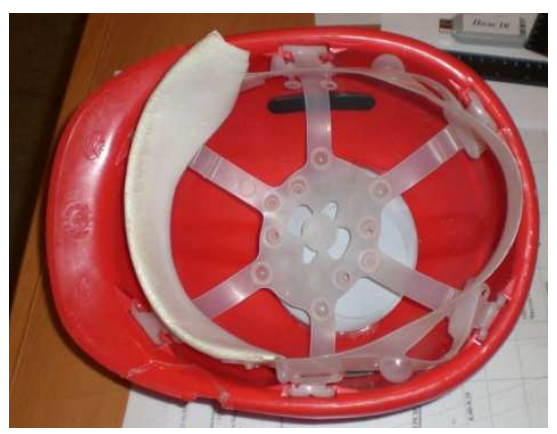

(a)

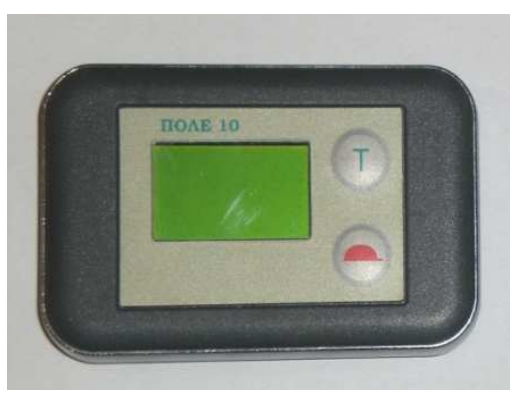

(b)

Figure 1. The device for measurement level of electric field action on a worker: a) the receiver portion of the device, containing the sensor; b) the body of the device. (Device designed by the author).

\section{Finite element models of Electric Field distortion by a Human Body}

The electromagnetic field of industrial frequency satisfies the condition of quasi-stationary fields under which we can neglect the transformation of some types of fields to the other and consider separately the effect of electric and magnetic fields on the objects.

The solution to any problem on the electric fields calculation can be done analytically or using numerical methods.
In this paper, the finite element method was used for electric fields calculation.

Calculated the three-dimensional model of the problem includes.

1. The air environment which is in the form of a parallelepiped. Uniform vertical DC electric field is formed in this area. The parallelepiped has a size of $1 \mathrm{~m}$ in width, and length, and $3 \mathrm{~m}$ in height (Fig. 2).

2. The three-dimensional model of the human body is located inside this area (Fig. 2).

3 . The foots of the human body model can be on the level of the bottom side of the environmental area or separated from it by the special insert having various thickness and dielectric properties. This insert is intended for modeling footwear soil (Fig.2).

4. Distribution of electric field intensity is described by equations $[3,4]$ :

$$
\operatorname{div} \vec{D}=\rho_{\text {free }}
$$

Here, $\overrightarrow{\mathrm{D}}$ is the vector of an electric induction, $\rho_{\text {free }}$ is the volumetric density of free charges.

$$
\vec{D}=\varepsilon_{0} \varepsilon_{r} \vec{E},
$$

Here, $\overrightarrow{\mathrm{E}}$ is a vector of intensity of an electric field, $\varepsilon_{0}=8.85 \cdot 10^{-12} \mathrm{~F} / \mathrm{m}$ is the electric constant describing electric properties of the vacuum, $\varepsilon_{\mathrm{r}}$ is the relative dielectric permeability of substance.

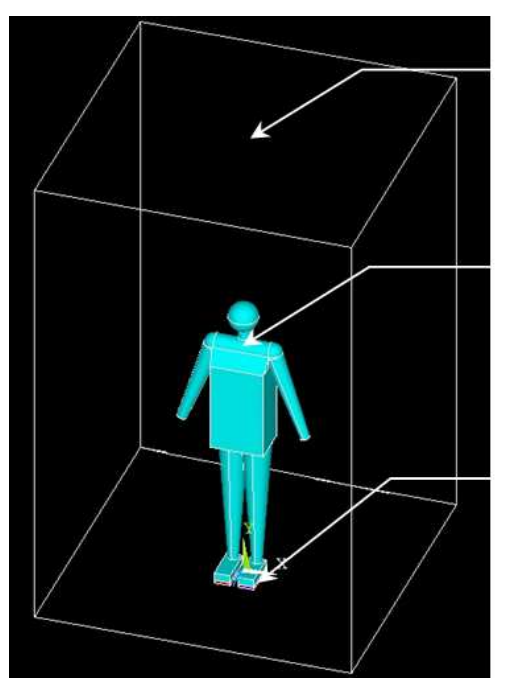

$$
\begin{gathered}
\text { The air } \\
\text { environment } \\
\text { in the form } \\
\text { of a parallelepiped } \\
\text { model } \\
\text { of the human } \\
\text { body }
\end{gathered}
$$

The insert is imitating shoes

Having substituted (3) in (2) we shall receive:

$$
\operatorname{div} \varepsilon_{0} \varepsilon_{r} \vec{E}=\rho_{\text {free }}
$$

Intensity of an electric field can be expressed through electric potential $\varphi$, inV.

$$
\vec{E}=-\operatorname{grad} \varphi
$$


Having substituted (5) in (4) we shall receive:

$$
\operatorname{div}\left(-\varepsilon_{0} \varepsilon_{r} \operatorname{grad} \varphi\right)=\rho_{\text {free }}
$$

For a finding solution of this equation in calculated area, it is necessary to set boundary conditions.

Let's choose a boundary condition of the first sort [3]:

$$
\left.\varphi\right|_{B}=f_{1}
$$

Here, B is the border of a field (a surface limiting calculated area), $\mathrm{fl}$ is the given function distribution of potential on the border of the field.

In the next calculation, the bottom side of a parallelepiped of the air environment is grounded.

$$
\left.\varphi\right|_{b s}=0
$$

The constant potential was applied to the top side (Ts) of a parallelepiped of the air environment for formation uniform, vertical external electric field in relation to model of the human body model.

$$
\left.\varphi\right|_{T s}=\text { const }
$$

Calculation was carried out in an engineering package of finite element analysis (ANSIS).

The general view of the body model is given on Fig. 2

The model is created by using of simplified geometrical figures. In such details as fingers of hands and legs of the person, ears, eyes, lips, a nose and other details in display of a head since their description essentially would complicate and without that complex enough geometry of the model, and also, in our opinion are excluded from consideration, would not result in increase of accuracy of calculation.

Extremely important question at model construction of a human body is the choice of the anthropometrical characteristics which varied in the further calculations and which

\begin{tabular}{|c|c|c|c|c|c|}
\hline \multirow{2}{*}{ \# } & \multirow{2}{*}{$\begin{array}{l}\text { The name of } \\
\text { measurement }\end{array}$} & \multicolumn{3}{|c|}{ The value of measurement } & \multirow{2}{*}{$\begin{array}{l}\text { Deviation } \\
\text { from } \\
\text { average } \\
\text { value, } \%\end{array}$} \\
\hline & & Small & Medium & Large & \\
\hline 1 & Height, mm & 1538 & 1720 & 1880 & 20.42 \\
\hline 2 & $\begin{array}{l}\text { Vertical size } \\
\text { of body, mm }\end{array}$ & 595 & 610 & 670 & 20.59 \\
\hline 3 & $\begin{array}{l}\text { Height } \\
\text { of shoulder, mm }\end{array}$ & 1260 & 1424 & 1570 & 21.77 \\
\hline 4 & $\begin{array}{l}\text { Height } \\
\text { perineum, mm }\end{array}$ & 665 & 816 & 900 & 28.80 \\
\hline
\end{tabular}
remain constant, and also the assignment of electromagnetic properties of a human body in the model.

Table 1. The variable vertical sizes of the man body.

As the initial assumption it was accepted, that distribution of intensity of an electric field around of a body of the person will be defined by its height, and also the form and proportions of the top part of a body. Key parameters describing the vertical sizes of a body of the person are: height of the person, height of a shoulder, height of a level of eyes, and height perineum. All other dimensions of a body of the person (length of a trunk, length of legs etc.) are defined by addition or subtraction of the sizes above mentioned.

Three sets of the vertical body parameters were selected for research of electric field distortion. These are appropriate to small, medium, and large dimensions of the person (Table 1).

Depth of a chest cage, width of shoulders, and a circle of a head were considered as the parameters describing the form

\begin{tabular}{|c|c|c|c|c|c|}
\hline \multirow[b]{2}{*}{ \# } & \multirow{2}{*}{$\begin{array}{l}\text { The name of } \\
\text { measurement }\end{array}$} & \multicolumn{3}{|c|}{ The value of measurement } & \multirow{2}{*}{$\begin{array}{l}\text { Deviation } \\
\text { from } \\
\text { average } \\
\text { value, } \% \\
\end{array}$} \\
\hline & & Small & Medium & Large & \\
\hline 1 & $\begin{array}{l}\text { Width } \\
\text { of shoulders, mm }\end{array}$ & 395 & 474 & 485 & 18.99 \\
\hline 2 & $\begin{array}{l}\text { Depth of a chest } \\
\text { cage, mm }\end{array}$ & 170 & 215 & 250 & 37.21 \\
\hline 3 & $\begin{array}{l}\text { Circle of a head, } \\
\mathrm{mm}\end{array}$ & 475 & 540 & 600 & 23.15 \\
\hline 4 & $\begin{array}{l}\text { Radius of a head, } \\
\mathrm{mm}\end{array}$ & 75 & 80 & 95 & 25.00 \\
\hline
\end{tabular}
of the top part of a human body, Table 2 .

Table 2. The variable parameters describing the size and the form of the top part of a human body.

Unchangeable parameters of the model are shown in Table 3. According [5], the main components of human body are the skeletal muscles, a fatty, and bones mass. These components are usually considered at modeling processes in a human body.

Taking into account, that our problem includes calculation of electric field intensity in external space near a surface of a

\begin{tabular}{|c|c|c|}
\hline$\#$ & The name of measurement & $\begin{array}{l}\text { Model } \\
\text { parameters } \\
\text { of a human } \\
\text { body, mm }\end{array}$ \\
\hline 1 & Radius of cross section of a neck & 40 \\
\hline 2 & $\begin{array}{l}\text { Radius of the top part of the chest cage submitted by } \\
\text { half of the cylinder }\end{array}$ & 60 \\
\hline 3 & Radius of the humeral joint submitted by sphere & 61 \\
\hline 4 & Length of a hand & 600 \\
\hline 5 & $\begin{array}{l}\text { Radius of the top part of the hand submitted } \\
\text { by a truncated cone }\end{array}$ & 59 \\
\hline 6 & $\begin{array}{l}\text { Radius of the bottom part of the hand submitted } \\
\text { by a truncated cone }\end{array}$ & 30 \\
\hline 7 & $\begin{array}{l}\text { Radius of the bottom part of the leg submitted } \\
\text { by a truncated cone }\end{array}$ & 40 \\
\hline 8 & Length the stops, submitted by a parallelepiped & 240 \\
\hline 9 & Width the stops, submitted by a parallelepiped & 150 \\
\hline 10 & Height the stops, submitted by a parallelepiped & 50 \\
\hline
\end{tabular}
human body placed in an electric field, we consider human body filled with a homogeneous material.

Table 3. The unchangeable parameters of a human body in the model. 


\section{Results of calculation of the Electric Field Distortions by a Human Body}

The electric field distortion degree is estimated by coefficient of distortion determined according the formula (10):

$$
K_{\text {dist }}=E_{\text {dist }} / E_{\text {undist }}
$$

Where, $E_{\text {dist }}$ is the module of the electric field intensity distorted by a human body, $E_{\text {undist }}$ is the undistorted module of electric field intensity.

The coefficient of distortion is calculated on different distance from the top point of the model head. In the next calculations, the three situations are considered: 1) undistorted uniform vertical electric field (Fig. 3a); 2) distorted electric field when human body model has direct contact with the ground (Fig. 3b); 3) distorted electric field when human body model is isolated from the ground (Fig. 3b).

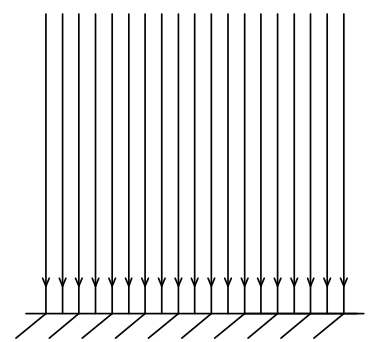

(a)

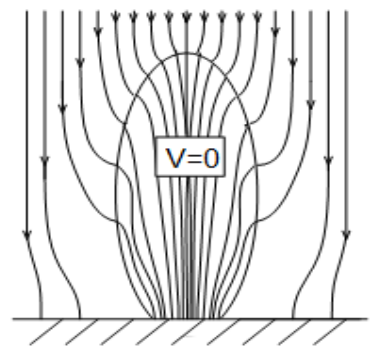

(b)

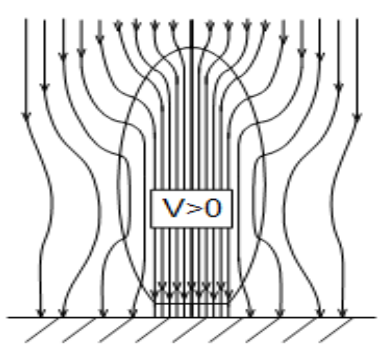

(c)

Figure 3. Distribution of electric field lines: a) in uniform electric field, b) a human body model has direct contact to the ground, (c) when model is isolated from the ground (analog sole of footwear).

The initial data for calculation are: specific resistance of air $=1014 \Omega * \mathrm{~m}$ : The relative dielectric permeability of air equal 1: specific resistance of human body $1.85 \Omega * \mathrm{~m}$, the relative dielectric permeability of human body 80000 . The potential of the ground is equal zero, and the potential top of the side parallelepiped is equal $15 \mathrm{kV}$. Intensity of an external uniform electric field is $5000 \mathrm{~V} / \mathrm{m}$.

\subsection{Human Body Model Has Direct Contact with the Ground}

Fig. 4 depicts results of calculation of the electric field intensity vectors (directions and values) when model is grounded. The change coefficient of distortion of an electric field on distance from $2 \mathrm{~cm}$ up to $1 \mathrm{~m} 20 \mathrm{~cm}$ up from the top point of the model head is shown on Fig. 5. The greatest change (more than in 3 times) of electric field is on a distance from $2 \mathrm{~cm}$ up to $10 \mathrm{~cm}$. Taking into account, that mobile devices of the electric field control level is the most convenient to mount on a worker helmet, the further calculations is carried out in this zone.

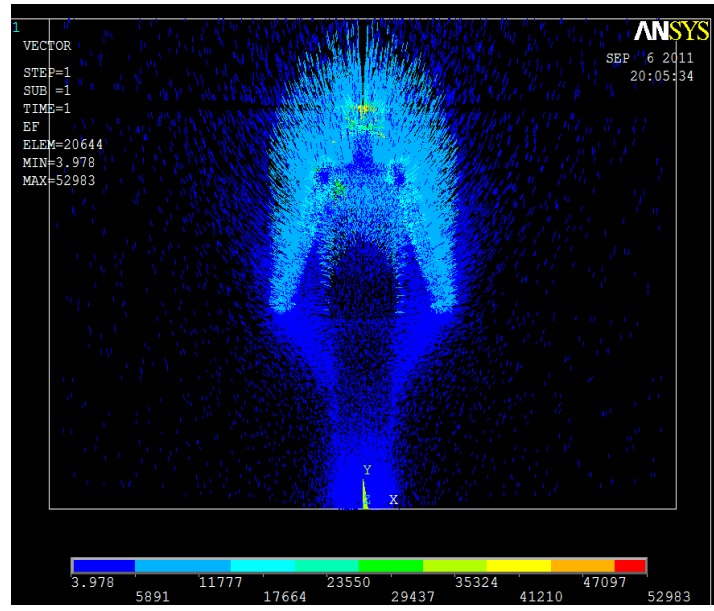

Figure 4. Results of calculation of an electric field when human body model is grounded.

According Fig. 5 data, it is visible, that on significant distance from a head model (more than $1 \mathrm{~m}$ ) the coefficient of distortion of an electric field is not equal to unit and equal about 1.3.

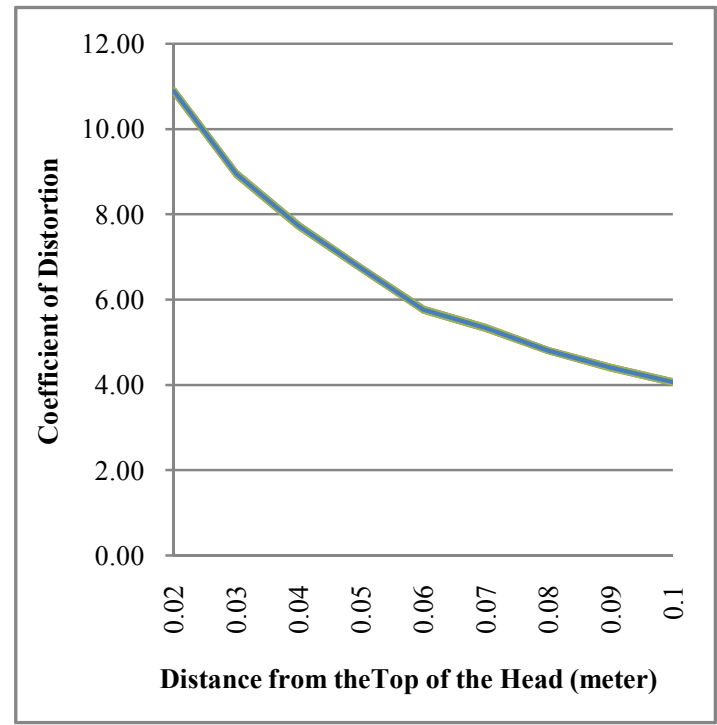

(a) 


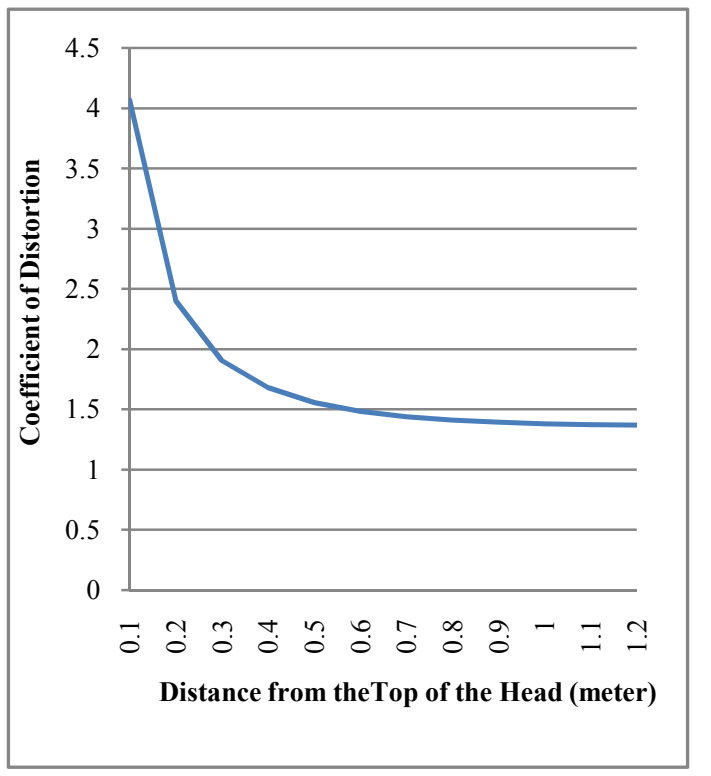

(b)

Figure 5. Coefficient of an electric field distortion as function of a distance up from the head of the model: a) from $0.02 \mathrm{~m}$ to $0.1 \mathrm{~m}, \mathrm{~b}$ ) from 0.1 to $1.2 \mathrm{~m}$.

In Table 4, values of electric field intensity and coefficient of distortion calculated for human body model, having average value of height $(172 \mathrm{~cm})$, width of shoulders $(47.4 \mathrm{~cm})$, depths of a chest cage $(21.5 \mathrm{~cm})$, and radius of a head $(8 \mathrm{~cm})$. Calculations are executed for the points up from the head (from $2 \mathrm{~cm}$ to $10 \mathrm{~cm}$ ).

Table 4. Values of an electric field intensity and coefficient of distortion calculated for human body model.

\begin{tabular}{|c|c|c|c|c|c|}
\hline \multirow{2}{*}{$\begin{array}{l}\text { Distance } \\
\text { from } \\
\text { a head, } \\
\text { meter }\end{array}$} & \multicolumn{4}{|c|}{ Electric field intensity, $\mathrm{V} / \mathrm{m}$} & \multirow{2}{*}{ 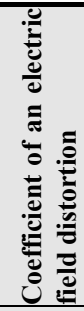 } \\
\hline & $\begin{array}{l}\text { Vector } \\
\text { module }\end{array}$ & $\begin{array}{c}\text { Projection } \\
\text { to axis } X \\
E_{X}\end{array}$ & $\begin{array}{c}\text { Projection } \\
\text { to axis } Y \\
E_{Y}\end{array}$ & $\begin{array}{c}\text { Projection } \\
\text { to axis } Z \\
E_{Z}\end{array}$ & \\
\hline 0.02 & 54467.0 & -853.3 & -54459.0 & -273.7 & 10.89 \\
\hline 0.04 & 38655.0 & -383.0 & -38650.0 & -495.0 & 7.73 \\
\hline 0.06 & 28852.0 & 105.9 & -28848.0 & 511.9 & 5.77 \\
\hline 0.08 & 24064.0 & -40.1 & -24064.0 & 4.5 & 4.81 \\
\hline 0.10 & 20337.0 & -13.5 & -20336.0 & -148.9 & 4.07 \\
\hline
\end{tabular}

According the data in Tab. 4, the highest values of electric field intensity have vertical component (a projection to axis Y). Prevalence of the vertical field component allows use the only one-coordinate electric fields sensor at creation of the mobile device for measurement electric field. On the basis of calculations which results are submitted on Fig. 6, the height of the human body have essential influence on a degree of electric field distortion and it should be taken into account at measurement of intensity of the distorted electric field by the mobile device.

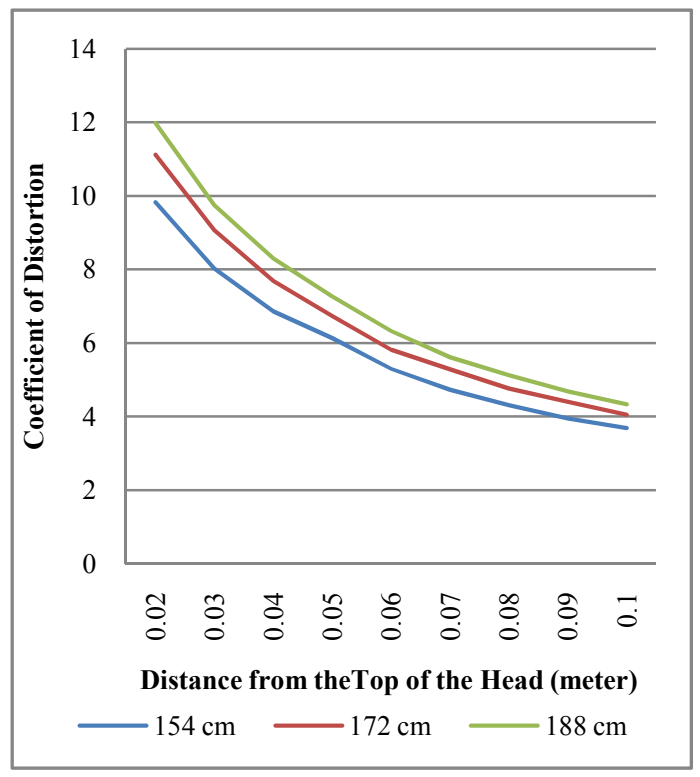

Figure 6. Influence of the human body height on a degree of electric field distortion.

The Influence of a chest cage cross section and size of a head on a degree of an electric field distortion is shown in Fig. 7. According to these data, the change of coefficient distortion is minimal and may not be taken into account.

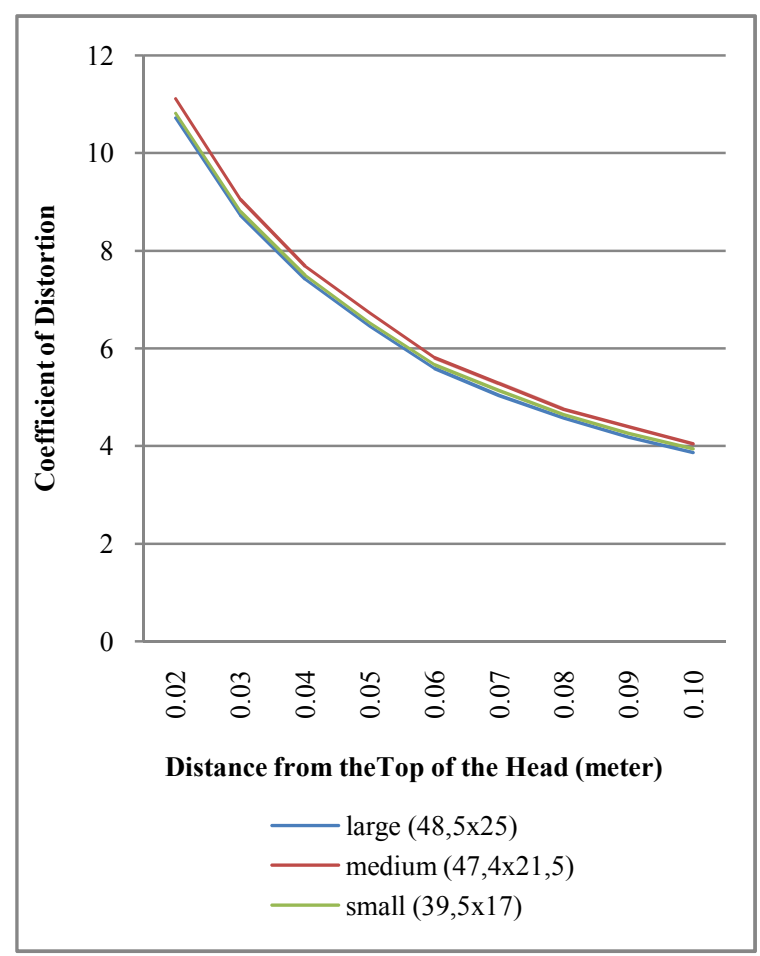

(a) 


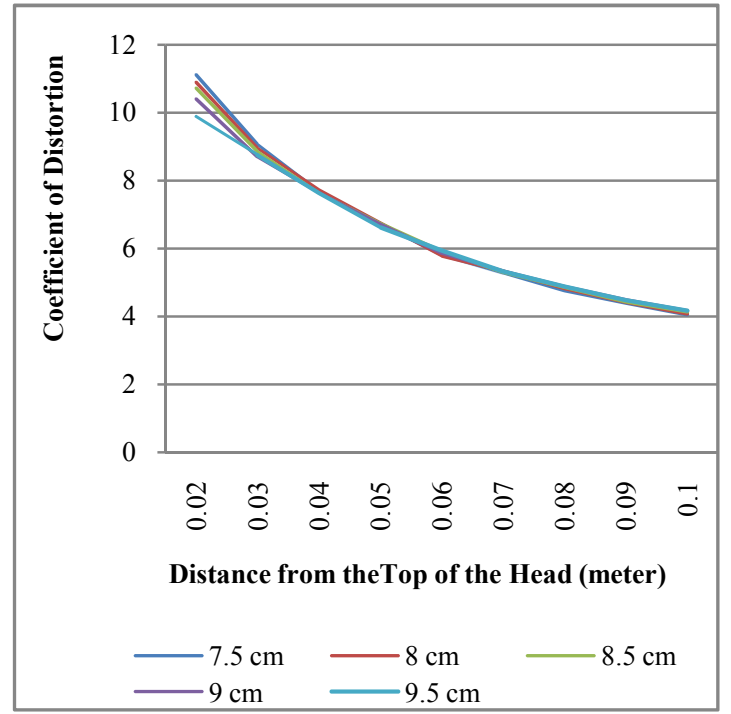

(b)

Figure 7. Electric field distortion by human body with height $172 \mathrm{~cm}$ and different size of: a) the cross section human body (width of shoulders and depth of a chest cage; b) the size of a head.

\subsection{Human Body Model is Isolated from the Ground}

In the second step calculation, the human body model is separated from the ground by a footwear sole of different thickness and different dielectric permeability.

Fig. 8 shows the directions and values of electric field intensity vectors. The field is distorted by a human body isolated from the ground by a sole thickness of $2 \mathrm{~cm}$ and having relative dielectric permeability equal 1 .

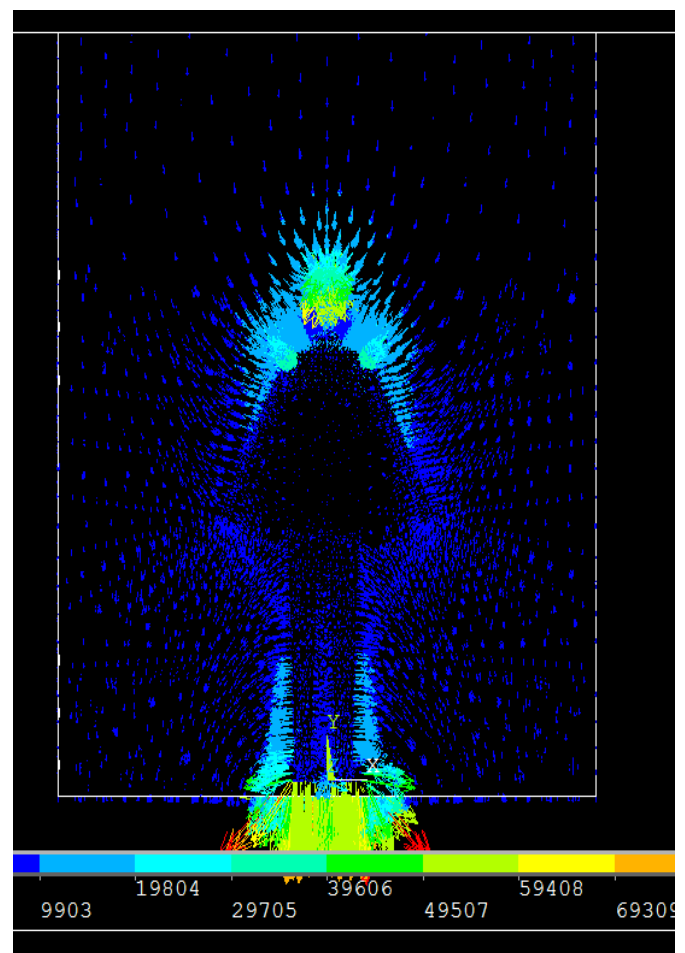

Figure 8. Results of calculation of an electric field distortion when a human body isolated from the ground.
The model of the human body has average size of: height, width of shoulders, depth of a chest cage, and the head.

The comparison coefficient of distortion of an electric field for the human body having direct contact to the ground and isolated from it is shown in Fig. 9. At distance up to $30 \mathrm{~cm}$ from the model head the coefficients of distortion are different, and on the greater distance distinction becomes minimal. There is a reduction in coefficient of distortion when human body is isolated from the ground.

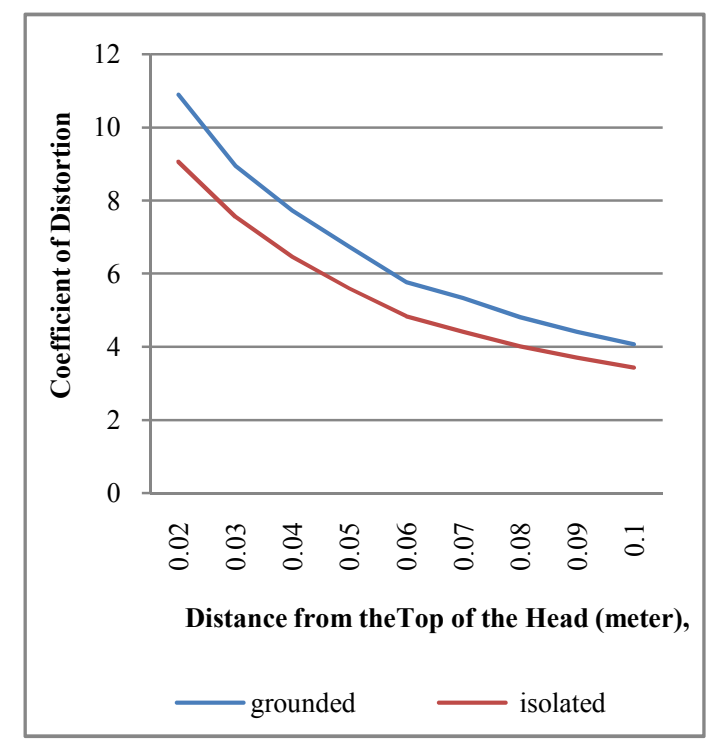

(a)

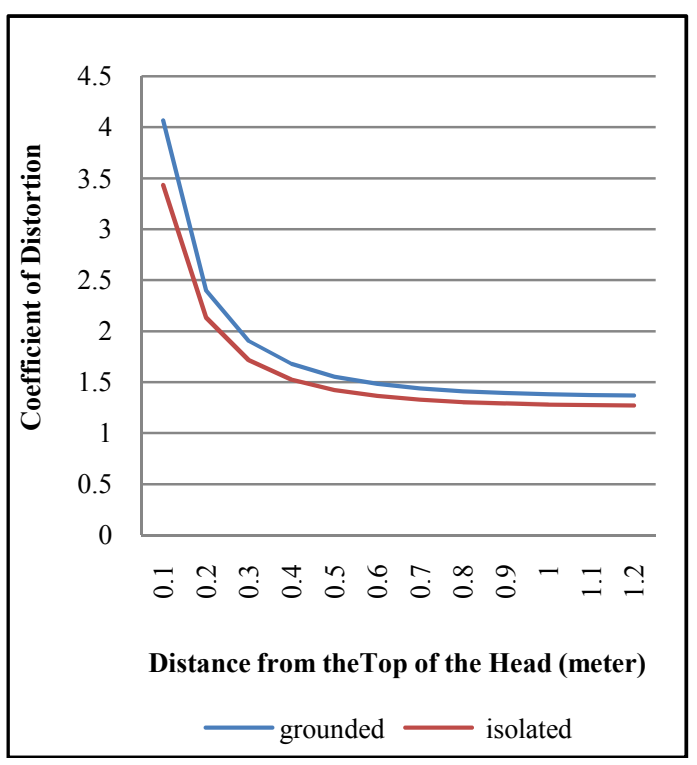

(b)

Figure 9. Comparison coefficients of electric field distortion when human body model grounded and isolated from ground: a) Distance from $0.02 \mathrm{~m}$ to $0.1 \mathrm{~m}$; b) Distance from $0.1 \mathrm{~m}$ to $1.2 \mathrm{~m}$.

Dependence the coefficient of distortion from thickness of the footwear sole is depicted on Fig. 10. Thickness of a sole varied in a range from $1 \mathrm{~cm}$ to $4 \mathrm{~cm}$. According results of calculations, the distortion of an electric field decreases 
with increase of thickness of a sole.

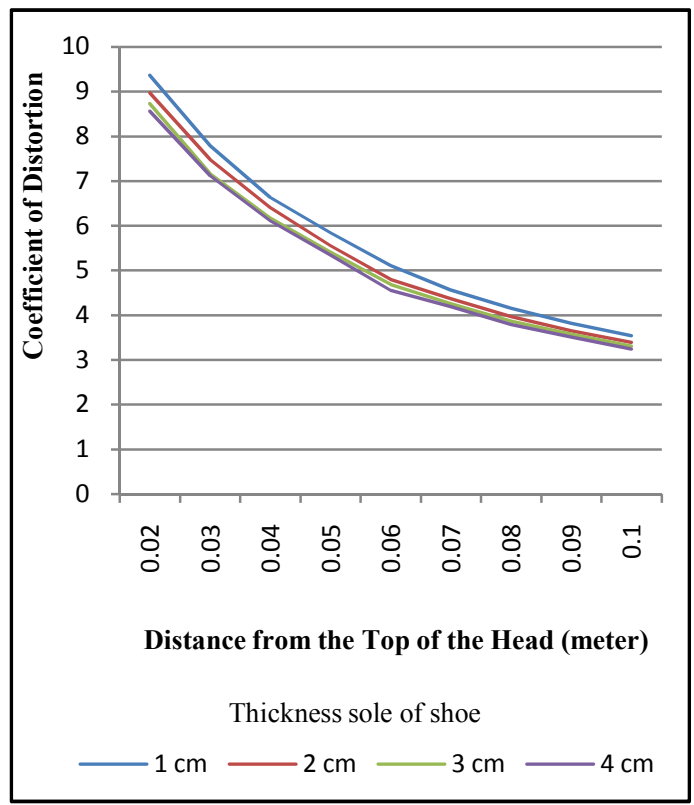

Figure 10. Dependence of an electric field distortion from distance up from model head for different footwear sole thicknesses.

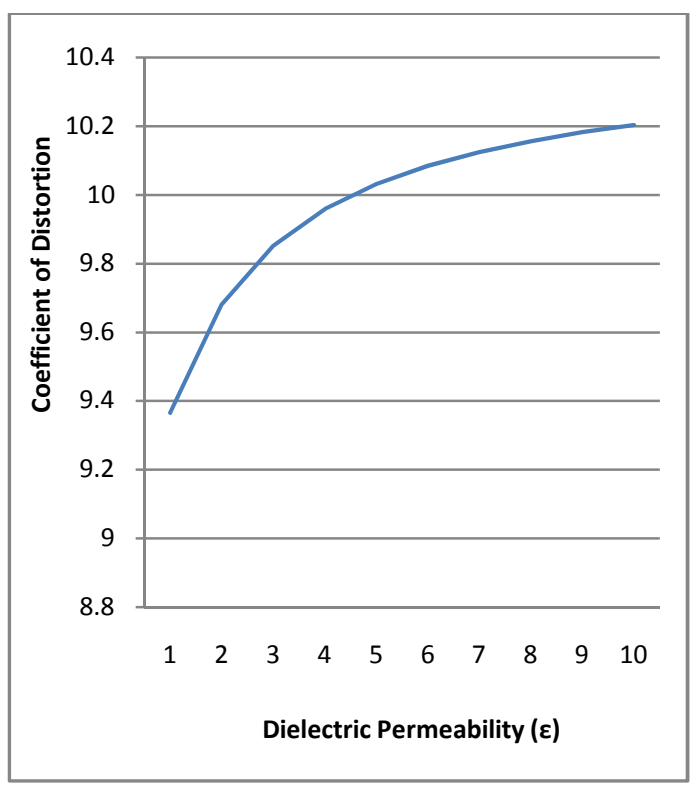

Figure 11. Influence of dielectric permeability of a footwear sole on a degree of distortion of an electric field. Height of human body is $172 \mathrm{~cm}$ and distance from head is $1 \mathrm{~cm}$.

Fig. 11 shows dependence of the coefficient of distortion from dielectric permeability of the footwear soil.

Minimal value distortion is observed at dielectric permeability equal 1 . With increase of dielectric permeability of the sole, coefficient of distortion is grows.

\subsection{Dependence Electric Field Distortion from the Body Arm Position}

Besides of the anthropometrical characteristics and parameters of footwear, the position of the person arms influence on electric field distortion. Calculations of change the degree of an electric field distortion were carried out depending on position in space of one or both arms of person body model. Calculation was carried out for a person body model with average parameters of a height, dimension of a chest cage, and a head. Fig. 12 depicts of the body model images with raised one (Fig. 12 b-d) and two (Fig. 12 e-g) arms. Results of model calculations are depicted in Fig. 13 and Fig. 14.

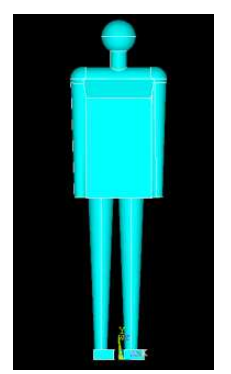

(a)

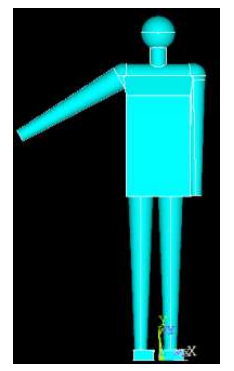

(b)

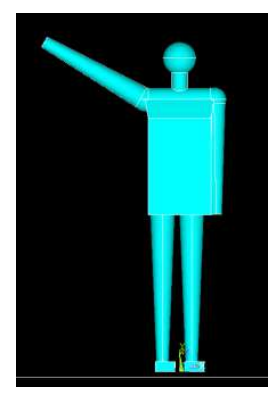

(c)

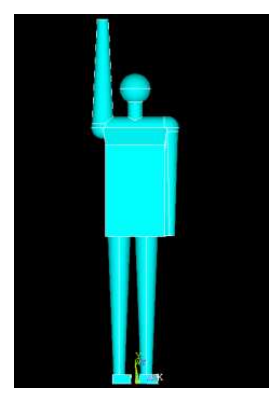

(d) 


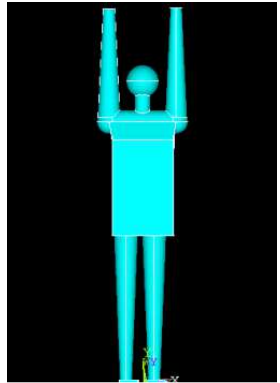

(e)

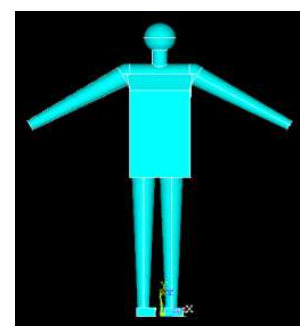

(f)

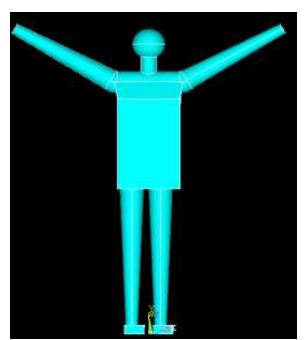

(g)

Figure 12. Human body models with: a) the arms are lowered along a body; b) one arm is raised on angle of 60 degrees; c) one arm is raised on angle 120 degrees; d) one arm is raised on angle 180 degrees; e) two arms are raised on angle 180 degrees; f) two arms are raised on angle 60 degrees; g) two arms are raised on angle 120 degrees.

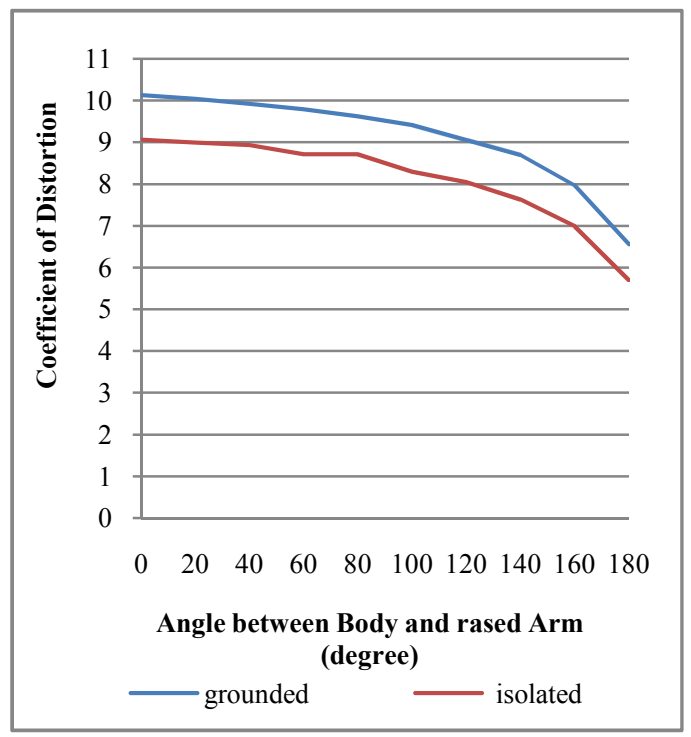

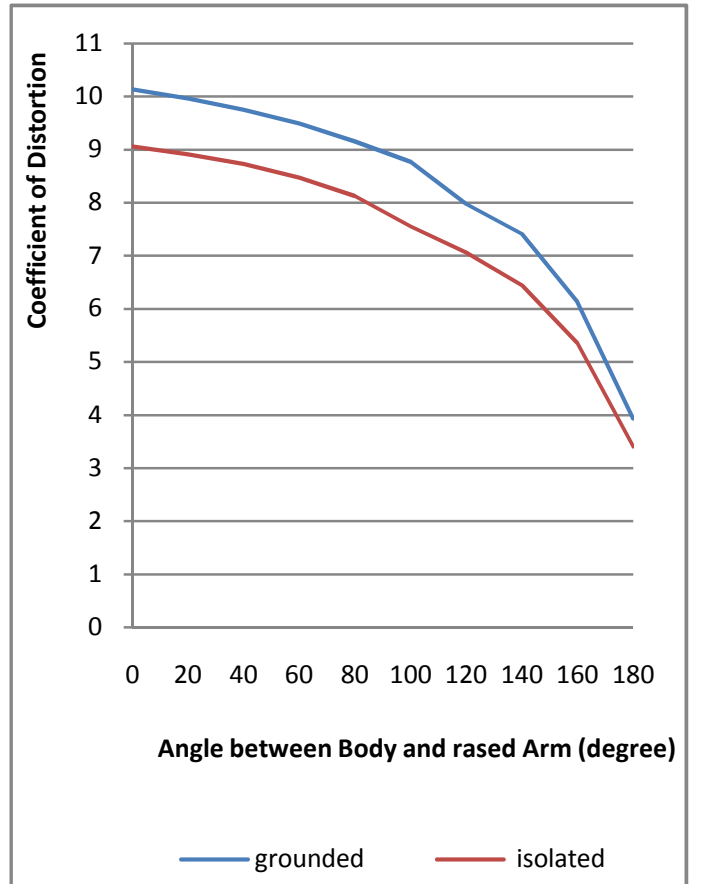

(b)

Figure 13. Distortion of an electric field for the earthed and isolated human body: a) with one arm raised; b) with two arms raised.

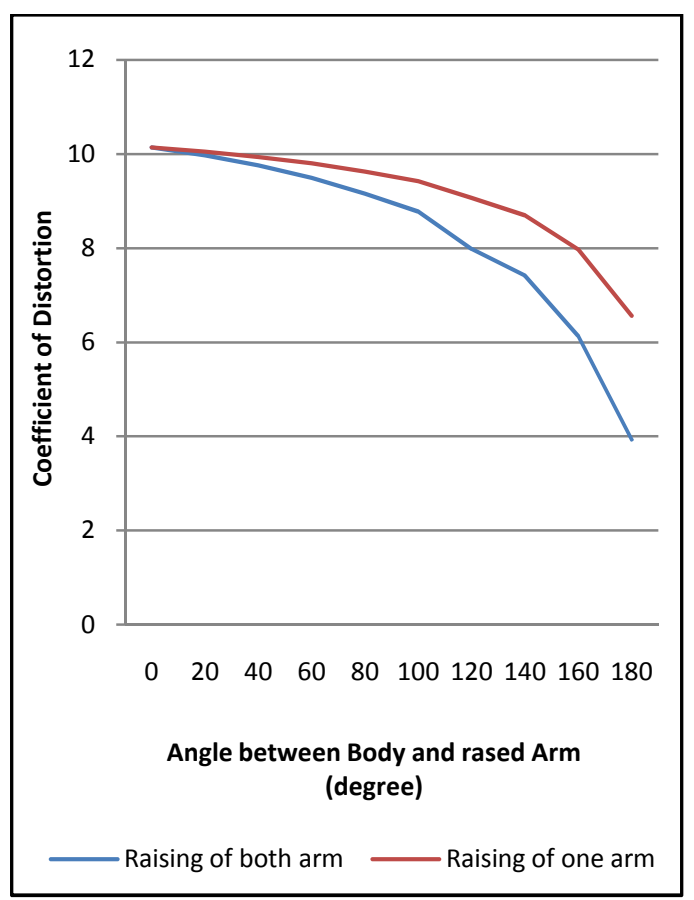

(a) 


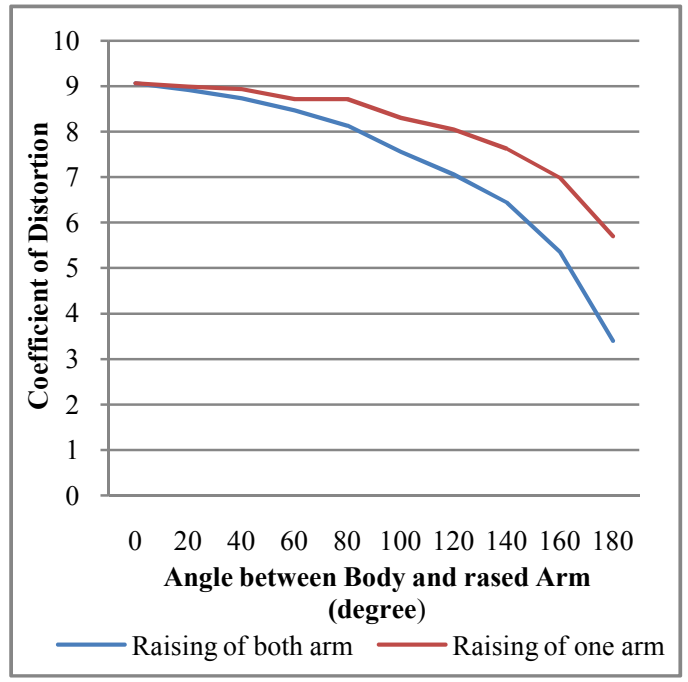

(b)

Figure 14. Distortion of an electric field at raise of one or two arms: a) for the earthed human body; b) for isolated human body.

According Fig. 13, 14, and data submitted in Table 5 at rise of arms, there is a reduction of electric field intensities above head of the human body.

Table 5. Distorted electric field intensity on distance of two centimeters above head of human body at rise of arms on various angles (intensity of an external uniform electric field is $5000 \mathrm{~V} / \mathrm{m}$ )

\begin{tabular}{|c|c|c|c|c|}
\hline \multirow{3}{*}{$\begin{array}{l}\text { Angle } \\
\text { between } \\
\text { body } \\
\text { and } \\
\text { raised arm, } \\
\text { degree }\end{array}$} & \multicolumn{4}{|c|}{ Distorted electric field intensity by human body, $\mathrm{V} / \mathrm{m}$} \\
\hline & \multicolumn{2}{|c|}{ The body is grounded } & \multicolumn{2}{|c|}{$\begin{array}{c}\text { The body is isolated fron } \\
\text { ground }\end{array}$} \\
\hline & $\begin{array}{l}\text { Raised } \\
\text { one arm }\end{array}$ & $\begin{array}{l}\text { Raised } \\
\text { two arms }\end{array}$ & $\begin{array}{l}\text { Raised } \\
\text { one arm }\end{array}$ & $\begin{array}{l}\text { Raised } \\
\text { two arms }\end{array}$ \\
\hline 0 & 50668 & 50668 & 45303 & 45303 \\
\hline 20 & 50216 & 49812 & 44944 & 44566 \\
\hline 40 & 49641 & 48754 & 44666 & 43661 \\
\hline 60 & 48994 & 47436 & 43582 & 42341 \\
\hline 80 & 48102 & 45748 & 43582 & 40638 \\
\hline 100 & 47071 & 43839 & 41484 & 37746 \\
\hline 120 & 45298 & 39854 & 40207 & 35272 \\
\hline 140 & 43471 & 37037 & 38103 & 32229 \\
\hline 160 & 39826 & 30627 & 34933 & 26768 \\
\hline 180 & 32809 & 19645 & 28511 & 17012 \\
\hline
\end{tabular}

The reduction of the electric field intensity at rise of one arm on angle 180 degrees is about $37 \%$, compared with the value received for 0 degrees, and at rise of two arms is about $62 \%$.

The received results calculation of the electric field distortion requires verification. It can be carried out in the experimental way.

\section{Experimental Verification}

The analyzer of electric and magnetic fields EFA-300 NARDA, equipped with not directed antenna sensor and having the maximal three percent error, was used for experimental research

Men, as they make overwhelming majority of the persons who are carrying out works on service in substation, were involved for participation in experiment.

For each participant of an experiment were fixed its physical data: height, a circuit of a head, width of shoulders, depth of a chest cage, which were used further in a calculation.

Experiment was carried out on the open area of substation with $\mathrm{AC}$ voltage $500 \mathrm{\kappa V}$. In this case, researchers have the big range change of electric field intensity on a rather small territory and have plane (specially prepared) surface of the ground that is convenient for accommodation of the equipment.

The relative positioning of the examinee and the measuring device is shown on Fig. 12.

Readout of indications of the measuring device were carried out for undistorted electric field (Fig.15 a) and distorted by a human body (Fig. 15b).

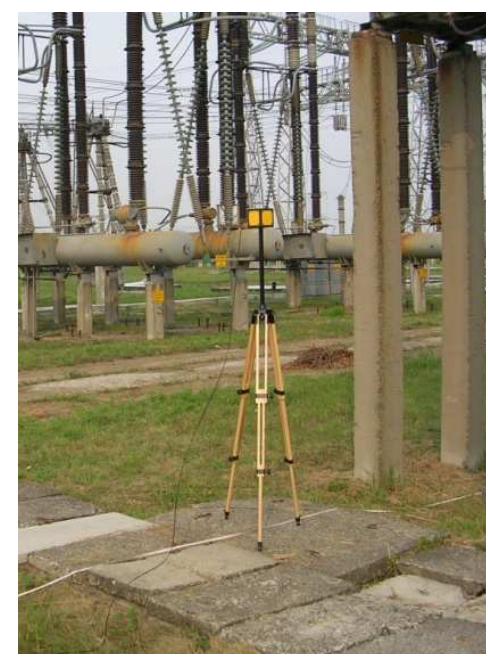

(a)

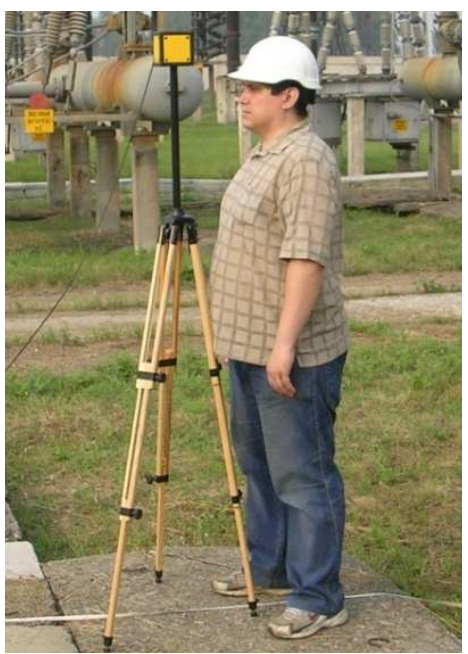

(b)

Figure 15. Accommodation of the measuring device in free space (a), and also mutual accommodation of the device and the examinee(b).

The results of the measurements received for an undistorted and distorted by participant body electric field are 
given in Table 6.

Table 6. The results of measurements received for undistorted and distorted by a participant body electric field.

\begin{tabular}{lllll}
\hline $\begin{array}{l}\text { Results of the } \\
\text { experiment }\end{array}$ & \multicolumn{2}{l}{ Electric field intensity, V/m } & & \\
\cline { 2 - 5 } & Projectionto axis $\mathbf{X} \mathbf{E}_{\mathbf{X}}$ & Projection to axis $\mathbf{Y} \mathbf{E}_{\mathbf{Y}}$ & Projection to axis $\mathbf{Z} \mathbf{E}_{\mathbf{Z}}$ & Vector module \\
\hline $\begin{array}{l}\text { In free space } \\
\text { Distorted by a body } \\
\text { of the examinee }\end{array}$ & 1500 & 12450 & 3900 & 13200 \\
\hline
\end{tabular}

The appropriate physical parameters of the examinee to us, therefore, in calculation were used some values of were introduced in calculated model.

The dielectric permeability of a footwear sole is unknown dielectric permeability of a sole material. Results of calculation are given in Table 7.

Table 7. Results of Calculation the Electric Field Intensity for Comparison with Results of the Experiment.

\begin{tabular}{|c|c|c|c|c|c|c|}
\hline \multirow[b]{2}{*}{$\#$} & \multicolumn{4}{|c|}{ Electric field intensity, $\mathrm{V} / \mathrm{m}$} & \multirow{2}{*}{$\begin{array}{l}\text { Dielectric permeability } \\
\text { of a sole material, } \varepsilon_{r}\end{array}$} & \multirow[b]{2}{*}{$\begin{array}{l}\text { Error relative to } \\
\text { experiment }\end{array}$} \\
\hline & $\begin{array}{l}\text { Projection to axis } \\
\mathbf{X ~ E}_{\mathbf{X}}\end{array}$ & $\begin{array}{l}\text { Projection to axis } \\
Y E_{Y}\end{array}$ & $\begin{array}{l}\text { Projection to } \\
\text { axis } Z E_{Z}\end{array}$ & Vector module & & \\
\hline 1 & $-14,58$ & -20423 & -10104 & 22786 & 2 & 7,00 \\
\hline 2 & $-16,02$ & -21069 & -10620 & 23594 & 4 & 3,70 \\
\hline 3 & $-16,77$ & -21403 & -10887 & 24013 & 6 & 2,73 \\
\hline 4 & $-17,22$ & -21608 & -11051 & 24270 & 8 & 0,94 \\
\hline 5 & $-17,53$ & -21747 & -11162 & 24365 & 10 & 0,55 \\
\hline 6 & $-18,97$ & -22393 & -11678 & 25255 & 100 & 3,08 \\
\hline
\end{tabular}

At results of calculation, the maximal received error is less than $10 \%$. According [2], the value of $10 \%$ is allowable for calculation of electric field intensity.

\section{Conclusion}

1. According the results of the electric field calculation, the highest values field intensity has vertical component. It allows use only one-coordinate electric fields sensor at creation of the mobile device for electric field measurement.

2. The greatest influence on electric field distortion has height of the person. Influence of parameters of a chest cage of the person (width of shoulders and depths of a chest cage) is minimal.

3. At insertion of a footwear sole between the model human body and the ground, the electric field distortion decreases. The increase of dielectric permeability of footwear sole leads to increase electric field distortion.

5. At rise of human arms, there is a decrease of electric field intensity above the head of a person. At angle 180 degrees between the body and raised arms, decrease of electric field is about $37 \%$ compared with the value received for 0 degrees, and at raise of two arms, decrease is about $62 \%$.

4. Comparison, of computer modeling results with the experimental data received on an open area of substation $500 \mathrm{kV}$, shows that the greatest difference in data not exceeded $7 \%$.

\section{References}

[1] General Characteristic of Electric Field Intensity of 500-kV Outdoor Switchgears, Okrainskaya, I.S., Sidorov, A.I., Tryapitsyn, A.B., Babin, A.V., Goldshtein, M.I., Blinkova, L.L., Syzrantseva, E.A. Power Technology and Engineering. 2006. V. 40. \# 2, pp. 127-130

[2] Sanitary Rules and Norms. 2.2.4.1191-03 Electromagnetic fields in industry conditions 
[3] Kolechitsky, E.S. Calculation of electric fields of a high voltage devices: High schools manual / I.P. Белоедова, U.V.Eliseev, E.S.Kolechitsky etc.; under edition. E.S.Kolechitskogo. - M.: Publishing house MEI, 2008. $-248 \mathrm{p}$.

[4] Bessonov, L.A. Theoretical basics of electrical engineering. An electromagnetic field: Textbook. - 9 ed. - M.; Gardariki, 2001. $-317 \mathrm{p}$.

[5] Cherepnev, I.A. Biological effects under influence of electromagnetic waves / Systems of management, navigation, and signalling. -2007.- pp 118-124

[6] Kuznetsov, A.N. Biophysics of low frequency electromag- netic influences. The manual - M.: MFTI, 1994. - 164 p.

[7] Okrainskaya, I.S, Staff Protection in Super High Voltage Electric Substations by Using of the Electric Field Measurement Devices/ I.S. Okrainskaya, A.I. Sidorov, S.P. Gladyshev //2012 IEEE International Conference on Electro Information Technology, Indiana University-Purdue, University Indianapolis, Indianapolis USA, May 6-8, Catalog Number CFP12EITCDR. - 2012. - 6 p.

[8] A.I. Sidorov, I.S. Okrainskaya, S.P. Gladyshev, Measurement of Super High Voltage Transmission Line Electric Field Effecting on the Environment. IEEE EIT 2011, Paper 43, Mancato, May15-17, 2011. 